\title{
Simulating pesticides in ditches to assess ecological risk (SPIDER): I. Model description.
}

\author{
Fabrice G. Renaud $^{\mathrm{a}, \mathrm{b},}{ }^{*}$, Pat H. Bellamy ${ }^{\mathrm{a}}$, Colin D. Brown ${ }^{\mathrm{a}, \mathrm{c}}$
${ }^{a}$ Cranfield University, School of Applied Sciences, Natural Resources Department, Integrated Earth System Sciences Institute, Cranfield, Bedfordshire, MK43 0AL, UK
${ }^{\mathrm{b}}$ United Nations University, Institute for Environment and Human Security, UN Campus, Hermann-Ehlers-St. 10, Bonn 53113, Germany \\ ${ }^{\mathrm{c}}$ Environment Department, University of York, Heslington, York, YO10 5DD, UK \& Central Science \\ Laboratory, Sand Hutton, York, YO41 1LZ, UK
}

10

11

Proofs should be sent to the corresponding author: United Nations University, Institute for Environment and Human Security, UN Campus, Hermann-Ehlers-St. 10, Bonn 53113, Germany

*Corresponding author. Tel.: +49 228 8150211; fax: +49 228 8150299; E-mail address: renaud@ehs.unu.edu 


\begin{abstract}
Risk assessment for pesticides in the aquatic environment relies on a comparison between estimated exposure concentrations in surface water bodies and endpoints from a series of effects tests. Many field- and catchment-scale models have been developed but there are no generally-applicable models that combine descriptions of pesticide entry into water via the major routes of exposure (particularly spray drift and drainflow) with fate in water. Models that are available range from simple empirical models to comprehensive, physically-based, distributed models that require complex parameterisation, often through inverse modelling methods. SPIDER (Simulating Pesticide In Ditches to assess Ecological Risk) was developed to address this gap and to simulate pesticide exposure within networks of small surface water bodies (ditches and streams) in support of ecological risk assessment for pesticides. SPIDER is a locally distributed, capacitance-based model that accounts for pesticide entry into surface water bodies via spray drift, surface runoff, interlayer flow and drainflow and that can be used for small agricultural catchments. This paper provides a detailed description of the model.
\end{abstract}

Keywords: Catchment, Model, Pesticide, Drainage, Surface water, Risk assessment 


\section{Introduction}

Understanding and managing the potential for impacts of pesticides on the aquatic environment relies on a comparison between estimated exposure concentrations in water bodies (primarily fieldedge systems comprising ditches, ponds and streams; FOCUS, 2002) and endpoints from a series of ecotoxicity tests. A significant amount is known about fate of pesticides applied to fields (e.g. Flury, 1996; Wauchope, 1996) and monitoring data at the catchment level indicate presence of certain pesticides in large water bodies (e.g. IFEN, 2002; Environment Agency, 2003). There is a clear need to understand and simulate behaviour of pesticides at the linking scale of small, field-edge water bodies. Indeed, the agricultural landscape as a cohesive unit comprising one or several farms is increasingly the scale of relevance for managing the way that pesticides are used.

Pesticide fate models that are currently available and could be considered for application in simulation of small catchments can be divided into three groups (Table 1). The RIVWQ model (Williams et al., 1999) is an example of a field-scale model applied at the catchment level. The tool links multiple unit-area simulations of the PRZM model (Carsel et al., 2000) to account for variations in land use, soil and weather across a watershed and an advection-dispersion model to address chemical fate and transport in the receiving water. The models that incorporate flow routing to and within surface water and have the flexibility to represent spatial heterogeneity in properties across the catchment are better matched to the task. There are large differences in purpose, scale, complexity and process descriptions.

The SWAT (Soil and Water Assessment Tool) model has been developed by USDA to assess the effect of management decisions on water, sediment, nutrient and pesticide yields in large river basins. (Arnold et al., 1998). SWAT is a physically-based, spatially-related model that compiles information about weather, soil properties, topography, natural vegetation, and cropping practices within a customised ArcView Interface. Sub-basins are divided into hydrologic response units that are unconnected units with the same landuse and soil. Algorithms governing movement of soluble and sorbed forms of pesticide from land areas to the stream network were taken from EPIC (Williams, 1995). SWAT incorporates a simple mass balance developed by Chapra (1997) to model the 
1 transformation and transport of pesticides in streams represented as a well-mixed layer of water

2 overlying a homogenous sediment layer.

MIKE-SHE is a fully distributed, continuous application model (time step 15 to 120 minutes) designed to incorporate all major land components of the hydrologic cycle, including overland sheet flow, channel flow, unsaturated sub-surface flow and saturated groundwater flow (Refsgaard and Storm, 1995). Additional modules allow simulation of transport of pesticides and other solutes, including specific descriptions of biodegradation and transport via macropore flow. The model is intended for application at scales from field to large watershed. The model requires a detailed set of input parameters to simulate pesticide transport at the catchment scale and this restricts its use to the study and management of highly characterised catchments. Recently, the model has been used as the basis for the pesticide registration tool PestSurf proposed for use in Denmark (Styczen et al, 2004). The MIKE-SHE model has been calibrated against detailed monitoring data for two catchments in Denmark. To reduce simulation time, all the water calculations are carried out in advance and cannot be changed by the user. The scenarios are built into an interface that allows the user to input information about properties and usage of the pesticide and to access results of the simulation.

The POPPIE (Prediction of Pesticide Pollution in the Environment) system is a GIS-based catchment scale model developed by the UK Environment Agency to predict concentrations of agricultural pesticides at the outlet of catchments throughout England and Wales (Brown et al., 2002). The aim is to support the design of pesticide monitoring programmes. The surface water model embedded in POPPIE (SWATCATCH) is a semi-empirical, distributed model based upon the calculation of flows and pesticide concentrations contributed by each soil hydrological type within a specific catchment. The performance of the model has been assessed in a validation exercise comparing simulations of frequency of detections, maximum concentrations and time series of exposure versus monitoring data for 29 catchments of varying character and size (Brown et al., 2002).

Routine use of catchment models for assessment and management of pesticides requires a tool that is both comprehensive in being able to address all major routes of entry of pesticides into surface water (spray drift, surface runoff and drainage) and that has reasonable parameter requirements. 
1 MIKE-SHE is the most comprehensive model available at present, but it can only be applied following

calibration against data from detailed monitoring programmes. Other models have mainly been derived in the United States and focus primarily on transport of pesticides in surface runoff. This paper presents a new model, SPIDER (Simulating Pesticides In Ditches to assess Ecological Risk) that was developed to address a gap in the available models. The aims for the model were to (a) account for pesticide entry into surface waters via the most important pathways with particular attention to entry via subsurface drains, (b) capture spatial variability within small catchments, (c) restrict the parameters as far as possible to those that can be easily measured or estimated, and (d) operate on a time-step that would capture transient peaks in concentration in surface water. A companion paper (Renaud and Brown, submitted) benchmarks the field transport component against the dual-porosity model MACRO which has been widely applied in simulating transport of pesticide through soil.

\section{Model description}

\subsection{Conceptualisation}

SPIDER is a research model that is locally distributed whereby the landscape is divided into a series of fields and ditch/stream segments. Computations are carried on an hourly time step. SPIDER is conceptualised for landscapes with high densities of ditches with a majority of the fields being drained and for wet-winter conditions such as those found in northern Europe. Ditches and streams are hydrologically connected to fields and receive pesticides dissolved in water originating from the fields via runoff, interlayer flow or drainflow. They can also receive pesticides directly via spray drift. Water and pesticides are then routed through the series of ditches and stream segments to the outlet of the catchment. SPIDER is intended to simulate pesticide concentrations in catchments of up to $10 \mathrm{~km}^{2}$; this limitation is a practical constraint rather than a computational one.

The model has two major modules. The first relates to processes taking place in the fields. In this part, movement and fate of water and pesticides is simulated in crops (if present) and in the soil. The soil profile is automatically divided into layers of no more than $10 \mathrm{~cm}$ thickness and computations are carried out in sequence in each layer. In addition, the A horizon is subdivided into a 2-cm thick 
1 "mixing layer" that allows applied pesticides to mix with the soil water and the horizon containing

2 drains has a 10-cm thick "drained" layer centred on the depth of the drains. SPIDER is a capacitance model whereby water is assumed to move under gravity alone when some threshold values of water content are reached. The second module relates to processes in ditch and stream segments. Each segment is associated with one or several fields and water is routed using the Muskingum method.

SPIDER was developed to be as flexible as possible, namely (a) there are no restrictions on the length in time of the simulation; (b) there are no limits on the number of fields that can be simulated; (c) a pesticide can be applied on multiple occasions throughout a simulation period and some of the properties associated with the pesticide can be changed at each application; and (d) SPIDER allows for several crops to be simulated for each individual field, and the crops can be different in successive seasons.

SPIDER was coded using the object-oriented $\mathrm{C}++$ language to facilitate updating and improvement. In the present version, input files are entered manually into a Microsoft Access database. The requirement for separate parameters for each field or ditch imposes the practical limitation on the scale of application for SPIDER. In addition, two weather files are required: one containing hourly rainfall data and one containing daily values for maximum and minimum air temperature, relative humidity, global solar radiation and wind speed. The latter file is used to compute daily reference evapotranspiration.

\subsection{Evapotranspiration}

Daily reference evapotranspiration $\left(E T_{r}\right)$ is calculated with the FAO Penman-Monteith equation (Allen et al., 1998):

$$
E T_{r}=\frac{0.408\left(R_{n}-G\right)+\gamma \frac{900}{T_{a}+273} u_{2}\left(e_{s}-e_{a}\right)}{\Delta+\gamma\left(1+0.34 u_{2}\right)}
$$

where $E T_{r}$ is in $\mathrm{mm} \mathrm{d}^{-1}, R_{n}$ is the net radiation at the crop surface $\left(\mathrm{MJ} \mathrm{m}^{-2} \mathrm{~d}^{-1}\right), G$ is the soil heat flux density $\left(\mathrm{MJ} \mathrm{m}^{-2} \mathrm{~d}^{-1}\right), T_{a}$ is the mean daily air temperature at $2 \mathrm{~m}$ height $\left({ }^{\circ} \mathrm{C}\right), u_{2}$ is the wind speed at 2 
$1 \mathrm{~m}$ height $\left(\mathrm{m} \mathrm{s}^{-1}\right), e_{s}$ is the saturation vapour pressure $(\mathrm{kPa}), e_{a}$ is the actual vapour pressure $(\mathrm{kPa}), \Delta$ is

2 the slope of the vapour pressure curve $\left(\mathrm{kPa}^{\circ} \mathrm{C}^{-1}\right)$, and $\gamma$ is the psychrometric constant $\left(\mathrm{kPa}^{\circ} \mathrm{C}^{-1}\right)$. Input parameters required to calculate $E T_{r}$ are elevation, longitude, maximum and minimum daily temperatures, daily average relative humidity, daily global radiation, wind speed and height of measurement for wind speed. As suggested by Allen et al. (1998), $G$ is not computed in the model and is set to zero.

Hourly $E T_{r}$ is determined by considering the times of sunrise and sunset. Actual crop evapotranspiration is calculated by multiplying $E T_{r}$ with crop and water stress coefficients that are calculated with a minor modification of the method of Allen et al. (1998) to account for a heterogeneous soil:

$E T_{a}=E T_{r} \cdot K_{c} \cdot K_{\theta}$

where $E T_{a}$ is the actual evapotranspiration $\left(\mathrm{mm} \mathrm{h}^{-1}\right), K_{c}$ is the crop coefficient (-), and $K_{\theta}(-)$ is a coefficient that accounts for water stress.

Reference crop evapotranspiration $\left(E T_{r}\right)$ is calculated for a well watered hypothetical grass crop (Allen et al., 1998). Ground cover, canopy properties and aerodynamic resistance of the crop will be different for another crop and will also vary with crop growth stage. The agricultural season is broken down into several crop growth stages ('initial', 'crop development', 'mid-season' and 'late season') and a $K_{c}$ value is assigned to each. Values of $K_{c}$ are linearly interpolated between these stages. Duration of each stage and the equivalent $K_{c}$ values can be obtained from Allen et al. (1998). A value of 1.0 is assigned to $K_{c}$ when no crop is present.

The factor $K_{\theta}$ accounts for any water stresses the crop is subjected to. This coefficient typically varies between 0.3 and 1.0, the latter value reflecting no water stress. It is calculated with (Allen $e t$ al., 1998):

$T A W=\sum_{i}\left(\theta_{f c(i)}-\theta_{p w p(i)}\right) \cdot$ FracRoot 
$1 \quad D_{r}=\sum_{i}\left(\theta_{f c(i)}-\theta_{i(i)}\right) \cdot$ FracRoot

$2 \quad K_{\theta}=\frac{T A W-D_{r}}{(1-p) \cdot T A W}$

3

where $T A W$ is the total available water in the root zone $(\mathrm{mm}), \theta_{f c}$ is the soil water at field capacity

$(\mathrm{mm}), \theta_{p w p}$ is the soil water content at permanent wilting point $(\mathrm{mm}), \theta_{i}$ is the initial water content at the beginning of the simulation time step $(\mathrm{mm}), D_{r}$ is the root zone depletion $(\mathrm{mm}), p$ is the fraction of $T A W$ that a crop can extract from the root zone without suffering a water stress (set at 0.5), FracRoot is the fraction of the soil layer occupied by crop roots (-), and $i$ indicates the number for those soil layers occupied by crop roots. $D_{r}$ cannot be $<0$ and $K_{\theta}$ cannot be $>1$.

Calculations in Allen et al. (1998) are simplified because the soil is assumed homogeneous. In SPIDER, the soil profile is broken down into several soil layers with different values of $\theta_{f c}, \theta_{p w p}$ and $\theta$.

Water contents $\left(\theta_{f c}, \mathrm{TAW}\right.$, etc) are summed for the A-horizon when there is no crop or the root tip is above the lower boundary of the A-horizon or over the depth of soil exploited by the roots when the root tip extends below the A-horizon.

When roots are present in the soil, water is removed from each layer proportionally to the fraction of root length present in the layer. This implies that, at crop maturity and if there is enough water in the soil, significant amounts of water can be removed from the horizons below the A-horizon. During dry spells, these horizons can dry faster than the A-horizon (which can be re-wetted by small rainfall events) which is an unwanted artefact of our original conceptualisation. To limit this problem, SPIDER will remove water from the A-horizon only once two or more layers below the A-horizon reach permanent wilting point. that equals $E T_{r}$ multiplied by a pan coefficient (currently fixed at 0.75 ).

\subsection{Crop processes}




\subsubsection{Crop physiology}

SPIDER simulates root depth $(R D)$, leaf area index $(L A I)$ and the fraction of crop cover $(F C C)$ on a daily basis. Root depth is modelled according to Borg and Grimes (1986). Leaf area index is computed using empirical equations developed for the MACRO model (Larsbo and Jarvis, 2003). The fraction of soil covered by the plant plays an important role for the determination of interception of rainfall and sprayed pesticide. It is assumed that $F C C$ increases linearly from 0 to 0.1 (10\% cover) which corresponds to the 'initial phase' of crop growth (Allen et al., 1998). This is then followed by a rapid increase until $L A I=3$ when it is considered that the crop has reached effective full cover $(90 \%$ cover). A slightly modified version of the sigmoid curve in LEACHM (Hutson and Wagenet, 1992) is used to describe $F C C$ during that phase. Finally, once $L A I$ starts decreasing after crop maturity, FCC is reduced using the same equation for $L A I$ decrease.

\subsubsection{Water balance on crop canopies}

Dickinson (1984) suggested that the amount of water stored on a crop was dependent on the leaf area index $(L A I)$ :

$S_{c}=0.2 \cdot L A I$

where $S_{c}$ is the storage capacity of the canopy $(\mathrm{mm})$. The water balance at the crop canopy level (in $\mathrm{mm})$ is then given as:

$\theta c a n_{(t)}=\theta \operatorname{can}_{(t-1)}+R d_{(t)}-\operatorname{Ecan}_{(t)}-\operatorname{Pcan}_{(t)}$

where $\theta$ can is the water stored in the canopy, $R d$ is the depth of rain, Ecan is the amount of water lost from the canopy through evaporation, Pcan is the amount of rain in excess of $S_{c}$ that reaches the soil surface, and $t$ is a time index. Evaporation from the crop canopy is assumed to take place at the reference $E T$ rate. If the canopy is dry, then $E T_{r}$ has to be satisfied by soil evapotranspiration below the canopy. If the canopy is wet then the portion of $E T_{r}$ required to satisfy $E c a n$ is subtracted from $E T_{r}$ and the remainder of $E T_{r}$ is removed from the soil. Amounts of rain and evaporation received and 
removed to/from the soil surface are calculated after computing rainfall intercepted by the crop canopy and subsequent re-evaporation.

\subsubsection{Crop pesticide balance}

The pesticide mass balance (in $\mathrm{mg}$ ) in the crop canopy is given by:

$$
\operatorname{PLcan}_{(t)}=\operatorname{PLcan}_{(t-1)}+\operatorname{Spray}_{(t)}-\operatorname{Deg}_{(t)}-W O_{(t)}
$$

where PLcan is the pesticide load on the canopy, Spray is the load intercepted by the crop canopy during spraying, Deg is the amount of pesticide lost on the crop canopy via degradation and other loss mechanisms and $W O$ is the amount of pesticide washed-off from the crop canopy. Degradation is computed using first-order kinetics and the FOCUS (2002) default half-life of 10 days is assumed if no degradation coefficient is available. The FOCUS (2002) approach was slightly modified to compute wash-off in SPIDER:

$W O=P L c a n-P L c a n \cdot e^{\left(-F C \cdot P_{c a n}\right)}$

$$
F C=0.0016 \cdot S o l^{0.3832}
$$

where $F C$ is a foliar extraction coefficient $\left(\mathrm{mm}^{-1}\right)$ that is dependent on the solubility of the pesticide (Sol in $\left.\mathrm{mg} \mathrm{L}^{-1}\right)$.

\subsection{Soil processes}

\subsubsection{Soil temperature}

Field observations have shown that soil temperatures oscillate quasi-symmetrically around an average temperature (Wu and Nofziger, 1999). A sinusoidal equation was adopted in SPIDER to account for both the annual and diurnal variations of soil temperature (see Hillel, 1998):

$$
\left.T(z, t)=T_{a v, y}+\frac{A m p_{y}}{\exp \left(z / d d_{y}\right.}\right)\left[\sin \left(\omega_{y} t+\phi_{y}-z / d d_{y}\right)\right]+\frac{A m p_{d}}{\exp \left(z / d d_{d}\right)}\left[\sin \left(\omega_{d} t+\phi_{d}-z / d d_{d}\right)\right]
$$


$1 d=\sqrt{\frac{2}{\omega} \alpha}$

2

3

4

5

$\phi=t-t_{0}$

where $T(z, t)$ is the temperature at depth $z$ and time $t\left({ }^{\circ} \mathrm{C}\right), T_{a v, y}$ is the annual average temperature at the soil surface, Amp is the temperature amplitude at the soil surface $\left({ }^{\circ} \mathrm{C}\right), d d$ is the damping depth at which the temperature decreases to the fraction $1 / e(\mathrm{~mm}), \omega$ is the radial frequency and is $2 \pi / 24$ for the daily cycle and $2 \pi / 365$ for the annual cycle $\left(\mathrm{h}^{-1}\right.$ or $\left.\mathrm{d}^{-1}\right), \phi$ is the phase constant, the subscripts $\mathrm{d}$ and $\mathrm{y}$ refer to daily or annual, $\alpha$ is the soil thermal diffusivity $\left(\mathrm{mm}^{2} \mathrm{~h}^{-1}\right)$ and $t_{0}$ is the time of day or time of year when the average temperature occurs.

Thermal diffusivity is the ratio between the thermal conductivity and the volumetric heat capacity (Hillel, 1998):

$\alpha=\frac{K}{C_{v}}$

$K=\frac{\left(\theta_{f c} / z\right) \cdot K_{w}+f_{a} \cdot K_{a} \cdot R_{a}+f_{c} \cdot K_{c} \cdot R_{c}+f_{q} \cdot K_{q} \cdot R_{q}+f_{o m} \cdot K_{o m} \cdot R_{o m}}{\left(\theta_{f c} / z\right)+f_{a} \cdot R_{a}+f_{c} \cdot R_{c}+f_{q} \cdot R_{q}+f_{o m} \cdot R_{o m}}$

$C_{v}=\left(\theta_{f c} / z\right) \cdot C_{w}+f_{a} \cdot C_{a}+f_{c} \cdot C_{c}+f_{q} \cdot C_{q}+f_{o m} \cdot C_{o m}$

where $\alpha$ is in $\mathrm{m}^{2} \mathrm{~s}^{-1}, \theta_{f c}$ is the depth of water at field capacity $(\mathrm{mm}), z$ is the thickness of the soil layer $(\mathrm{mm}), K$ is the thermal conductivity $\left(\mathrm{J} \mathrm{m}^{-1} \mathrm{~s}^{-1} \mathrm{~K}^{-1}\right), f$ is the fraction of each constituent (-), $R$ is the ratio of each constituent relative to the water phase (-), $C$ is the specific heat of the constituent $\left(\mathrm{J} \mathrm{m}^{-3} \mathrm{~K}^{-1}\right)$, and the subscript $a, c, q$, and om stand for air, clay, quartz and organic matter, respectively. The following values, reviewed by Müller (2000) were used: $K_{w}=0.57, K_{a}=0.025, K_{c}=2.92, K_{q}=8.80$, and $K_{o m}=0.25 \mathrm{~J} \mathrm{~m}^{-1} \mathrm{~s}^{-1} \mathrm{~K}^{-1} ; R_{a}=1.4$, and all other ratios are 0.4; $C_{w}=4.180, C_{a}=0.001212, C_{c}=$

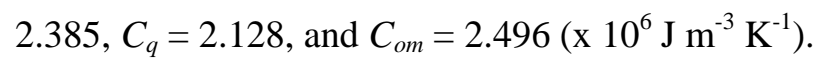


Information on the temperature at the soil surface is not usually available. It has therefore been replaced by air temperature in SPIDER. This approximation will yield an underestimate of soil surface temperatures when the soil is not covered, but is reasonable when the soil is covered by either a growing plant or crop residues. For each soil layer, the soil temperature is calculated at five equidistant points (including the layer boundaries) and an average soil temperature is determined for each layer. One difficulty of the above soil temperature equation is to determine the daily and annual values of $t_{0}$. An estimate of $t_{0}$ can be obtained by looking at daily and annual soil surface (or air) temperature fluctuations.

\subsubsection{Soil water balance}

Water movement as simulated by SPIDER depends on the water status of each soil layer. The reference soil water contents used for computation of water movement are:

- $\quad$ Permanent wilting point $\left(\theta_{p w p}\right)$ : in SPIDER, $\theta \geq \theta_{p w p}$.

- Field capacity $\left(\theta_{f c}\right)$ : this value is the trigger for vertical and lateral water movement. If $\theta \leq$ $\theta_{f c}$, water will not be transferred from one layer to the next. If $\theta>\theta_{f c}$ then water in excess of $\theta_{f c}$ is allowed to move.

- The water content at the boundary between micropores and macropores $\left(\theta_{\text {macro }}\right)$ : this value is a water content greater than $\theta_{f c}$ but smaller than $\theta_{\text {sat }}$. It represents the water content at which the micropore region is completely full and the macropore region is completely empty. If at any stage $\theta>\theta_{\text {macro }}$ then water is allowed to move rapidly to the next layer (within the limit of the saturated hydraulic conductivity). If $\theta_{f c}<\theta<\theta_{\text {macro, }}$ water movement will be a function of the unsaturated hydraulic conductivity of the soil. This allows for a separation of the flow domain into rapid and slow water movement to account for any preferential flow.

- $\quad$ Saturation $\left(\theta_{\text {sat }}\right): \theta$ cannot exceed $\theta_{\text {sat }}$.

For each soil layer the water balance (in $\mathrm{mm}$ ) is given by: 
$1 \quad \theta_{(t)}=\theta_{(t-1)}+R_{\text {soil }(t)}+\operatorname{Irr}_{(t)}-E T_{a(t)}-P_{(t)}-L M_{(t)}-D_{(t)}-R u_{(t)}$

2 where $\theta$ is the soil water content, $R_{\text {soil }}$ is the depth of rainfall reaching the soil surface, Irr is irrigation

3 reaching the soil surface, $E T_{a}$ is the actual evapotranspiration from the soil surface, $P$ is percolation,

$4 \quad L M$ is lateral movement, $D$ is drainage, and $R u$ is runoff. $L M, D$ and $R u$ are mutually exclusive in

5 SPIDER, meaning that the surface soil layer can only generate runoff, the soil layer containing the

6 drains can only generate drainflow, and all other layers can only generate lateral flow.

7

\subsubsection{Soil hydraulic properties}

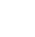

All the hydraulic properties of the soil can be entered directly by the modeller. Pedotransfer functions (PTF's) can be used if these properties are not known. The PTF's used are those reported by Evans et al. (1999), and they allow for the estimation of the van Genuchten parameters, saturated and residual water contents, water contents at field capacity and wilting point, air capacity and saturated hydraulic conductivity.

\subsubsection{Infiltration}

Rainfall patterns in northern Europe are characterised by low-intensity long-duration events, so the treatment of infiltration was kept simple: within an hourly time step all the rainfall is assumed to infiltrate the mixing layer. Any water in excess of field capacity within this layer is transmitted to the next layer. However if after vertical transfer of water to the next layer $\theta>\theta_{\text {sat }}$ then runoff is generated.

\subsubsection{Runoff}

Runoff is generated in two ways. First, when rainfall intensity exceeds the saturated hydraulic conductivity of the soil $\left(K_{s}\right)$ : 
$1 \quad R u=R_{\text {soil }}-K_{S}$

2 Second, when rain falls on an already saturated soil and after having accounted for percolation

3 (particularly active in undrained fields):

$4 \quad R u=\theta-\theta_{\text {sat }}$

5 where $\theta_{\text {sat }}$ is the saturated water content ( $\left.\mathrm{mm}\right)$.

6

\subsubsection{Percolation}

Percolation is handled differently depending on the position in the soil profile. This is done to allow preferential flow in the region above drains and to control the lower boundary condition. For horizons above the drained layer, it is assumed that water in excess of $\theta_{\text {macro }}$ moves at a rate equal to the saturated hydraulic conductivity. Therefore when $\theta>\theta_{\text {macro }}$ :

$P_{1}=\min \left(K_{S}, \theta-\theta_{\text {macro }}\right)$

where $P_{l}$ is the amount of water percolating at this stage of computation $(\mathrm{mm})$, and $K_{S}$ is the saturated hydraulic conductivity of the layer $\left(\mathrm{mm} \mathrm{h}^{-1}\right)$. To determine $\theta_{\text {macro }}$ the modeller needs to input a tension value $(<$ tension at field capacity) that characterises the state when macropores are empty. A rough guideline for $\theta_{\text {macro }}$ is the water content at $-1 \mathrm{kPa}$.

If at this stage of the computation $P_{1}<K_{S}$, more water is allowed to percolate. As soil hydraulic conductivity decreases rapidly with decreasing values of $\theta$, a step function is used at this second stage $\left(P_{2}\right)$. Within the one-hour time step, time remaining for percolation (after having allowed macropore flow) is calculated:

$$
\text { TimeAv }=1-\left(\frac{P_{1}}{K_{S}}\right)
$$

where TimeAv is the remaining time available for percolation within the 1-h time step (h). If TimeAv > 0, water content and percolation are calculated by dividing TimeAv into equally spaced intervals: 
$1 \quad$ TimeInt $=\frac{\text { TimeAv }}{\text { NbInt }}$

$9 \quad P_{2}=\sum_{N b I n t=1}^{6} P_{2, N b I n t}$

$$
P_{2}=\sum_{N b I n t=1}^{6} P_{2, N b I n t}
$$
later stage.

where TimeInt is the length of the time interval (h) and NbInt is the number of intervals required. For each one of these intervals the updated $\theta$ is used to calculate an unsaturated hydraulic conductivity, which is used for the next interval:

$P_{2}=\min \left(K_{u} \cdot\right.$ TimeInt,$\left.\theta-\theta_{f c}\right)$

where $K_{u}$ is the unsaturated hydraulic conductivity $\left(\mathrm{mm} \mathrm{h}^{-1}\right)$. The computation for $P_{2}$ is repeated NbInt times or terminated when $\theta=\theta_{f c}$, whichever comes first. At the end of each computation, $P_{2}$ is updated with the amount of percolation that was just calculated:

The percolation for the 1 -h time interval is $P=P_{1}+P_{2}$.

If at the start of the computation the macropores were empty $\left(\theta<\theta_{\text {macro }}\right)$ but $\theta>\theta_{f c}$, percolation is calculated with TimeAv set to $1 \mathrm{~h}$ and NbInt $=10$. The methodology reported above is then followed.

Calculations of water percolation in the layers below the drained layer are simplified. The initial soil water content is first used to calculate $K_{u}$. Percolation is then computed with:

$$
P=\min \left(K_{u}, \theta-\theta_{f c}\right)
$$

Finally, the modeller specifies a groundwater recharge value and if $\theta>\theta_{f c}$ in the deepest layer of the soil profile, that recharge value is the maximum rate of vertical water movement out of the profile. Water lost as recharge is currently assumed to leave the system and does not feed into the ditches at a

\subsubsection{Lateral movement}

If after percolation $\theta>\theta_{f c}$, additional water can be removed laterally as interlayer flow. This only concerns parts of the soil profile that are above the bottom elevation of a ditch (i.e. only water that can 
1 be directly intercepted by a ditch or stream is allowed to move laterally). The subroutine for lateral

2 water movement is based on the kinematic storage model of Sloan and Moore (1984) also used in 3 SWAT (Neitsch et al., 2002). The sequence of calculations involves the determination of the drainable 4 water volume, the drainable porosity, the saturated thickness, the flow velocity, and the discharge:

$5 \quad$ DrainabVol $=\left(\theta-\theta_{f_{c}}\right) \times$ Field $L \times 10^{-3}$

$6 \quad$ DrainabPor $=\frac{\left(\theta_{s}-\theta_{f c}\right)}{\text { depth }}$

$7 \quad$ SatThick $=\frac{2 \text { DrainabVol }}{\text { DrainabPor } \times \text { FieldL }}$

$8 \quad$ Flow Vel $=K_{l} \times \sin (\beta) \times 10^{-3}$

$9 \quad$ Disch $=$ SatThick $\times$ Flow Vel

$10 \quad L M=\frac{1000 \text { Disch }}{\text { FieldL }}$

where DrainabVol is the drainable volume of water stored in the saturated zone per unit width $\left(\mathrm{m}^{2}\right)$, FieldL is the field length (m), DrainabPor is the drainable porosity (-), depth is the depth of the soil layer (mm), SatThick is the saturated thickness (m), FlowVel is the flow velocity $\left(\mathrm{m} \mathrm{h}^{-1}\right), K_{l}$ is the (un)saturated lateral conductivity $\left(\mathrm{mm} \mathrm{h}^{-1}\right), \beta$ is the slope angle (rad), and Disch is the discharge $\left(\mathrm{m}^{2} \mathrm{~h}^{-}\right.$ $\left.15^{1}\right)$.

\subsubsection{Drainage}

One of two conditions is required for drainflow to be generated. First, when the layer below the drained horizon is saturated and $\theta>\theta_{f c}$ in the drained horizon or secondly, when a perched water table is formed in the drained horizon. For the first case, drainage depth is determined by:

$D=\min \left(K_{S}, \theta-\theta_{f c}\right)$ 
1 with $\theta \leq \theta_{\text {sat }}$. Considering the second case, a perched water table is formed when $\theta>\theta_{f c}$. The

2 proportion of saturated soil is first calculated (the rest of the horizon being kept at field capacity) and

3

$4 \quad D S=\frac{\left(\theta_{v}-\theta_{v, f c}\right) \times z}{\theta_{v, s a t}-\theta_{v, f c}}$

5

\subsubsection{Pesticide balance} is:

$\left.D=\min \left(K_{s}, \mid\left(\theta_{v, s a t}-\theta_{v, f c}\right) \times(D S-T h)\right]\right)$

where $D S$ is the thickness of the saturated layer $(\mathrm{mm}), \theta_{v}$ are the volumetric water contents of the soil $\left(\mathrm{mm}^{3} \mathrm{~mm}^{-3}\right)$, the subscript $f c$ and sat stand for field capacity and saturation, and drainflow is generated when $D S>T h(\mathrm{~mm})$. Th is arbitrarily set at $25 \mathrm{~mm}$. If during the second phase of the water balance calculation (i.e. when the model ensures that $\theta<\theta_{\text {sat }}$ in all layers) water is moved from the layer below the drained horizon and this brings $\theta$ above field capacity, then more drainage can be generated. However, the total drainage cannot exceed $K_{s}$.

Calculations for the soil pesticide balance vary depending on the type of layer being considered and whether preferential flow was allowed or not. The pesticide mass balance (in mg) for each layer

$$
\operatorname{Pest}_{(t)}=\operatorname{Pest} L_{(t-1)}+I L_{(t)}-P L_{(t)}-S D L_{(t)}-R L_{(t)}-\operatorname{Dr} L_{(t)}-L M L_{(t)}
$$

where Pest $L$ is the pesticide load in the layer, $I L$ are any inputs to the layer via application, spray drift, leaf washoff, or percolation from a layer above, $P L$ is the pesticide load transmitted via percolation, $S D L$ is the amount of pesticide lost via degradation, $R L$ is the pesticide load in runoff, $\operatorname{Dr} L$ is the pesticide load in drainage, and $L M L$ is the pesticide load in lateral flow.

The first step to calculate pesticide concentration in soil and water is to determine the volume of water that interacts with each soil layer. For the mixing layer, it consists in summing up the water content at the end of the time increment with the volumes of percolation and runoff. For the drainage 
1 layer, runoff is replaced with the volume of drainage and for the other soil layers, runoff is replaced

2 with interlayer flow.

The pesticide input to the soil layer is given by:

Mixing layer:

$$
\operatorname{Pest}_{(t)}=\operatorname{Pest}_{(t-1)}+P L_{i(t)}+\left(\operatorname{Pest}_{-} \operatorname{Appl}_{(t)} \cdot S A \cdot 100\right)
$$

All other layers: $\quad \operatorname{Pest}_{(t)}=\operatorname{Pest}_{(t-1)}+P L_{(t)}$

where $P L_{i}$ are inputs other than direct application (e.g. pesticide washoff from leaves in $\mathrm{mg}$ ), Pest_Appl is the pesticide application rate corrected for interception $\left(\mathrm{kg} \mathrm{ha}^{-1}\right), S A$ is the surface area of the field $\left(\mathrm{m}^{2}\right)$ and the factor ' 100 ' is used to convert units.

Once the pesticide load in the soil layer is known, the pesticide concentration in water is calculated:

$$
P L=P C_{w} \cdot S W+\left(k_{f} \cdot P C_{w}{ }^{N} \cdot S M\right)
$$

where $P C_{w}$ is the pesticide concentration in soil water $\left(\mathrm{mg} \mathrm{L}^{-1}\right), k_{f}$ is the Freundlich sorption coefficient $\left(\mathrm{mL} \mathrm{g}^{-1}\right), N$ is the Freundlich exponent (-), SW is the volume of water in the layer (L), and $S M$ is the mass of soil solids in the soil layer $(\mathrm{kg})$. In the model, $k_{f}$ is calculated from $k_{o c}$ and organic carbon content values provided by the modeller. This is not a fixed requirement, giving the user the flexibility to include influences on sorption of soil characteristics other than organic carbon.

A different computation scheme is followed in regions where preferential flow takes place. When calculating pesticide concentration in layer $n$, SPIDER first compares the volume of macropore water received by layer $\mathrm{n}$ from layer $n-1$ and the volume of macropore water leaving layer $n\left(P_{m a}\right)$. There are two possible situations:

- First, $P_{m a(n)} \geq P_{m a(n-1)}$. In this case, water and pesticide are transmitted from the soil matrix of layer $n$ to the macropore domain of layer $n$. This movement of water also transfers pesticide from one domain to the other.

- Second, $P_{m a(n)}<P_{m a(n-1)}$. The reverse of the above takes place, i.e. water and pesticide is moved from the macropore domain to the soil matrix. 
After transferring water and pesticide between the two domains, $P C_{w}$ is computed separately in the two pore regions of the layer. The amount of soil available for interaction with pesticides in the two flow domains is given by:
$S M_{m a}=S M \cdot f_{m a}$
and
$S M_{m i}=S M-S M_{m a}$

where $f_{m a}$ is the fraction of the total sorption capacity of the soil that is associated with macropores (-), and the subscripts $m a$ and $m i$ stand for macro and micropore, respectively.

Finally, pesticide transmitted via micropore flow in the drain layer is added to the layer but pesticide originating from macropore flow is directed straight to the drain and does not interact with the soil matrix. The amount of pesticide lost from each layer is calculated for each hydrological route (i.e. percolation plus runoff, interlayer flow or drainflow). It is assumed that in the mixing layer, pesticide is homogeneously mixed with the soil. However, the pesticide load moving via percolation to the next layer is split into pesticide moving via preferential flow and pesticide moving via matrix flow. This is done proportionate to the respective amounts of water flowing in these two domains.

Pesticide degradation follows first-order kinetics:

$\operatorname{Pest}_{(t)}=\operatorname{Pest} L_{(t-1)} \cdot e^{-k / 24}$ where $k$ is the degradation coefficient $\left(\mathrm{h}^{-1}\right)$ and the computation is carried out for a 1-h time step. The pesticide degradation coefficient can be adjusted according to the soil temperature (with the Arrhenius equation) and water content (Walker, 1973):

$k_{T, \theta}=k_{\text {Tref }, \theta r e f} \cdot e^{\frac{\mathrm{E} a \cdot\left(T_{(z, t)}-\operatorname{Tref}\right)}{R \cdot T_{(z, t)} \cdot \operatorname{Tref}}} \cdot\left(\frac{\theta}{\theta_{\text {ref }}}\right)^{B} \quad$ if $T>0$
$k_{T, \theta}=0$
if $T \leq 0$

where $k_{T, \theta}$ is the degradation coefficient at temperature $T$ and soil water content $\theta\left(\mathrm{d}^{-1}\right), k_{T r e f, \theta r e f}$ is the degradation rate determined at the reference temperature and water content $\left(\mathrm{d}^{-1}\right), E a$ is the activation energy (normally $\left.54000 \mathrm{~J} \mathrm{~mol}^{-1}\right), T_{(z, t)}$ is the soil temperature $(\mathrm{K}), T_{r e f}$ is the reference temperature at which the degradation coefficient was calculated $(\mathrm{K}), R$ is the gas constant $\left(8.314 \mathrm{~J} \mathrm{~mol}^{-1} \mathrm{~K}^{-1}\right), \theta_{\text {ref }}$ is 
the reference $\theta$ at which the degradation coefficient was calculated $(\mathrm{mm})$, considered to be field capacity in the model, and $B$ is a moisture exponent generally set at $0.7(-)$. If the modeller specifies that the degradation rate constant $(k)$ was determined from field measurements, then no correction for $\theta$ and $T$ are applied. Finally, the degradation rate is also adjusted for depth in the soil profile.

\subsection{Flow routing and pesticide fate in ditches}

\subsubsection{Water balance}

The water balance in each ditch segment is given by $\left(\right.$ all in $\left.\mathrm{m}^{3}\right)$ :

$V_{(t)}=V_{(t-1)}+D R_{(t)}+W I_{(t)}+B F_{(t)}-W O_{(t)}-E_{(t)}-\operatorname{Inf} f_{(t)}$

where $V$ is the volume of water in the ditch, $D R$ is the volume of rain falling on the ditch, WI represents the inputs of water to the ditch from the fields or other ditch segments, $B F$ is baseflow, $E$ is the volume of evaporation from the ditch, Inf is the amount of infiltration into the sediment bed of the ditch, and $t$ is a time increment that can be smaller than $1 \mathrm{~h}$ (see below). The following assumptions are made:

- All water inputs are added to the top-end of the ditch and the water is then routed through the ditch segment. Evaporation is subtracted from the input volume or, if no water is added to a ditch segment, from the volume of water already present in the ditch.

- The ditches are composed of two reservoirs, one for stagnant water and one for flowing water. This gives the modeller some flexibility if some ditches have obstacles that stop water from flowing altogether.

- Infiltration in the sediment bed only takes place when the drains are not flowing. It is assumed here that when drains are flowing, the water table is high and therefore infiltration is restricted. 
- In the current version of SPIDER, baseflow is a direct input value from the modeller. It is also assumed that baseflow remains constant over the simulation period.

Water input to a ditch or to a stream is routed using the Muskingum method (e.g. Fread, 1993; Viessman and Lewis, 1996):

$S=K_{m}[x I+(1-x) O]$

where $S$ is storage $\left(\mathrm{m}^{3}\right), I$ is inflow $\left(\mathrm{m}^{3} \mathrm{~s}^{-1}\right), O$ is outflow $\left(\mathrm{m}^{3} \mathrm{~s}^{-1}\right), x$ is a parameter that establishes the relative importance of $I$ and $O(-)$ and $K_{m}$ is a proportionality coefficient (s). The parameter $x$ varies between 0.0 and 0.5 . If inflow and outflow data are available $x$ and $K_{m}$ can be calculated (e.g. Viessman and Lewis, 1996). In the absence of inflow and outflow data, $x$ can be set at 0.2 and $K_{m}$ approximated by the travel time between two points in the reach.

Combining the equation above with the continuity equation and solving in finite difference form gives:

$\frac{I_{1}+I_{2}}{2}-\frac{O_{1}+O_{2}}{2}=\frac{S_{2}-S_{1}}{\Delta t}$

were $\Delta t$ are time increments and the subscripts 1 and 2 indicate the beginning and end of the increments. Rearranging the equation we obtain:

$O_{2}=C_{0} I_{1}+C_{1} I_{2}+C_{2} O_{1}$

$C_{0}=\frac{\Delta t+2 K x}{\Delta t+2 K-2 K x}$

$C_{1}=\frac{\Delta t-2 K x}{\Delta t+2 K-2 K x}$

$C_{2}=\frac{-\Delta t+2 K-2 K x}{\Delta t+2 K-2 K x}$

with $C_{0}+C_{1}+C_{2}=1$. As the equation is solved using finite difference, numerical stability must be satisfied and the time increment needs to be selected so that $2 K x<\Delta t<2 K(1-x)$. This is done automatically in the model, meaning that if $\Delta t$ needs to be smaller than $1 \mathrm{~h}$ (the time step of the model), intermediate calculations are automatically carried out but if $\Delta t$ needs to be greater than $1 \mathrm{~h}$, 
1 the user is prompted to select longer reach lengths for the simulation. Regardless of the value of $\Delta t$, the

2 model generates and hourly output of the outflow $\left(\mathrm{O}_{2}\right)$.

3 The difficulty with assimilating $K_{m}$ to the travel time is that the latter varies with flow stage. For

4 example, $K_{m}$ can be estimated using the following equations (Viessman and Lewis, 1996):

$5 \quad v=\frac{R h^{2 / 3} S l^{1 / 2}}{n}$

$6 \quad c=\frac{5}{3} v$

$7 \quad K=\frac{L}{c}$

9 where the first equation is Manning's equation for velocity in a channel, $v$ is the average flow velocity $10\left(\mathrm{~m} \mathrm{~s}^{-1}\right), R h$ is the hydraulic radius of the flow $(\mathrm{m}), S l$ is the slope of the channel bed $\left(\mathrm{m} \mathrm{m}^{-1}\right), n$ is a 11 coefficient that varies with the channels roughness properties $(-), c$ is the kinematic wave velocity (m $\left.12 \mathrm{~s}^{-1}\right)$ and $L$ is the length of the ditch (m). The $5 / 3$ coefficient in the second equation above characterises 13 a wide triangular channel. $R h$ is the ratio of the cross sectional area of the flow $(A)$ and the wetted 14 perimeter of the flow (Pw) (Neitsch et al., 2002):

$A=W_{b} d+z d^{2}$

$$
P w=W_{b}+2 d \sqrt{1+z^{2}}
$$

where $W_{b}$ is the ditch width at the bottom (m), $d$ is the flow depth (m), and $Z$ is the inverse of the side slope of the ditch and can be calculated with:

$$
Z=\frac{W_{b}-W_{t}}{2 d_{c}}
$$

where $W_{t}$ is the ditch's top width and $d_{c}$ is the ditch's depth. As can be seen from the set of equations above, $K_{m}$ will vary with $d$, whereas theoretically, $K_{m}$ should be a constant parameter for a given reach. The variation in $K_{m}$ affects the calculation of the outflow so a "representative" value of $K_{m}$ needs to be 
determined. For example, in SWAT, $K_{m}$ is calculated by assuming a full ditch and a ditch that is a tenth full, with one weighing coefficient assigned to both $K_{m}$ values (Neitsch et al., 2002). For the present version of SPIDER, $K_{m}$ is arbitrarily calculated assuming a half-full ditch.

Flow can be routed in the ditch once $K_{m}$ and $x$ are determined but the computation time $(C T)$ has to be within the range $2 K X<C T<2 K(1-X)$. If this is not the case the ditch has to be segmented and a new $K_{m}$ computed. SPIDER computes $K_{m}$ and $C T$ for every ditch, then selects the shortest $C T$ and uses that value to route water in all ditches. In a landscape with ditches of different sizes, the selected $C T$ is unlikely to respect the numerical criteria above for every ditch. Some ditches may therefore need to be segmented until the selected $C T$ can be applied to them. This is done automatically in SPIDER. The characteristics of each new segment are identical to those of the original ditch with the exceptions of (1) ditch length, (2) ditch $K_{m}$, and (3) the number of the ditches and fields it is associated with in the landscape. Water routing in the ditches is carried out in sequence, starting with the upstream segments. An artificial time delay is added to prevent water from the first ditch reaching the outlet of the catchment within one time step which, when the programme runs on a sub-hourly time step, would prove unrealistic in many situations. Therefore, outputs from one ditch segment are only transmitted to the next ditch segment during the following time step.

\subsubsection{Pesticide inputs to ditches dissolved in water}

The hydrological routes for pesticide entry in ditches are drainflow, surface runoff and interlayer flow. Only soil layers above the bottom depth of the ditches contribute interlayer flow to a ditch. The load of pesticide in each contributing soil layer is added to the loads from drainflow and surface runoff. These operations are carried out on an hourly basis. The total load of pesticide is then assumed to enter the ditch in its top section and is therefore allowed to interact with the entire length of the ditch. If the time step for flow routing in the ditch is smaller than $1 \mathrm{~h}$, pesticides inputs to ditches are divided proportionally to the fraction of time at which the computations are carried out.

\subsubsection{Pesticide inputs to ditches via spray drift}


SPIDER checks whether the wind runs over the sprayed field before reaching the ditch by comparing wind direction and the ditch orientation. Clearly if a ditch is upwind of a sprayed field, no spray drift needs to be computed. Spray drift calculations are only initiated if the receiving ditch has water in it, though a future development could consider suspension of pesticide on rewetting of a dry ditch.

To determine total drift loading to the ditch, basic spray drift is integrated over the width of the water body using the approach of FOCUS (2002):

$$
D_{0}=\frac{a\left(z_{2}{ }^{b+1}-z_{1}{ }^{b+1}\right)}{\left(z_{2}-z_{1}\right) \cdot(b+1)}
$$

where $D_{0}$ is the basic integrated spray drift $(\%), a$ is the y-intercept of the basic spray drift equation above (= 3.7676 in SPIDER), $b$ is the exponent of the basic spray drift equation above $(=-09786$ in SPIDER), and $z_{1}$ and $z_{2}$ are the distances of the near and far water edges from the spray nozzle (m). The distributed nature of the model means that it was important to have the potential to include interception of spray drift by vegetation in the zone between treated area and waterbody (Int). This is done on the basis of height of the intervening vegetation (C. Butler-Ellis, pers comm.) and is thus only applicable for dense vegetation (e.g. scrubland, hedges in full leaf):

$$
\text { Int }=0.833[V H-0.1] \quad D \geq 0
$$

where $V H$ is the margin vegetation height $(\mathrm{m})$ with a default value of $0.1 \mathrm{~m}$ (no interception).

Finally, the angle of incidence between the wind direction and the ditch is calculated. Computations for spray drift generally assume that wind direction is perpendicular to the field. This is seldom the case in a natural setting so an additional factor is added. A simple ratio of the angle of incidence to $90^{\circ}$ (right angle) is calculated. Final spray drift is:

$D_{f}=D_{0} C A$

where $D_{f}$ is the final percent drift entering the water body (\%) and $C A$ is an angle correction factor (-). Total pesticide load to the ditch is given by:

$S D L_{s d}=D_{f} \cdot A_{r} \cdot D L \cdot D W$ 
where $S D L_{s d}$ is the pesticide load due to spray drift $(\mathrm{mg}), A_{r}$ is the pesticide application rate $\left(\mathrm{kg} \mathrm{ha}^{-1}\right)$, and $D L$ and $D W$ are ditch length and ditch width, respectively (m).

\subsubsection{Pesticide fate in ditches}

Pesticide fate in ditches is determined after hydrological routing has been carried out and is computed at the same time step used for routing. The pesticide mass balance is given by (all in $\mathrm{mg}$ ):

$$
D P T L_{(t)}=D L_{(t-1)}+D P I_{(t)}-D P O_{(t)}-D D_{(t)}-D P L_{(t)}
$$

where DPTL is the total pesticide load in the ditch which comprises pesticide in water and pesticide in sediment, $D P I$ is the pesticide input to the ditch, $D P O$ is the amount of pesticide transmitted to the next ditch segment or reaching the catchment outlet, $D P D$ is degradation, $D P L$ is percolation and $\mathrm{t}$ is a time increment equivalent to $C T$. It is assumed that new water inputs displace water already in the ditch. Two cases are considered to move the pesticide from ditch to ditch. The first occurs when the outflow at the end of the ditch, $O_{(t)}$ is smaller than the volume of water originally present in the ditch $V_{(t-1)}$. In that scenario, all the calculations are carried out before the new water enters the ditch segment (the new water does not mix with the original water). The sequence of computation is as follows: (1) pesticide sorption to the ditch sediments, (2) degradation, (3) losses by percolation and (4) losses to the next ditch. Sorption is calculated as for sorption in soil with the modeller specifying a Freundlich coefficient $\left(k_{f}\right)$ and exponent $(N)$ specific to the bottom sediment. The modeller also needs to specify the thickness of the sediment layer that the pesticide interacts with. It is assumed that the entire volume of water in the ditch interacts with the sediment and a default depth for interaction sediment of $1 \mathrm{~cm}$ is suggested. For degradation, the modeller can specify two degradation rates: one for sediment and one for water. Degradation then follows first-order kinetics as in the soil compartment. Finally, the load of pesticide lost with moving water is computed by multiplying the concentration in water by the respective volume of water leaving the ditch. At the end of the time step, all incoming pesticide from upstream is added to the ditch. The second situation takes place when $O_{(t)}>V_{(t-1)}$. Here a portion of the incoming water flows through the ditch and exits the ditch within one time step. That water can carry a 
1 proportion of the total incoming pesticide load, the latter being allowed to interact with the ditch

sediment. The same calculation steps as above are then carried out.

Diffusion of pesticide into the sediment layer is not accounted for in the present version of SPIDER. For fast-moving systems, this omission may not be important providing the depth of interaction between pesticide and sediment is small. In addition, the processes of sorption to suspended sediments and macrophytes are ignored, but could be added as knowledge on these mechanisms increases (Hand et al., 2001; Moore et al., 2001).

\section{Conclusions}

SPIDER was developed to address a gap in the toolbox for aquatic ecological risk assessment for pesticides. It is a locally distributed model whereby the landscape is divided into a series of fields and ditch/stream segments. It is conceptualised for landscapes with high densities of ditches, where fields may be drained and for wet-winter conditions. The model simulates pesticide entry into ditches and streams via spray drift, surface runoff, interlayer flow and drainflow. Calculations are performed on an hourly time step, thus providing the modeller with a fine-resolution time series of pesticide concentrations leaving individual fields and in different stretches of ditches and streams throughout the catchment. Despite this resolution, data requirements for SPIDER remain reasonable and computation times are relatively short.

A companion paper (Renaud and Brown, submitted) reports on a sensitivity analysis and evaluation against two datasets of the field transport. Results suggest that the model is able to simulate peak concentrations of pesticide in water and predictions for transport in drainflow are very similar to those from the mechanistic, field-scale model MACRO (Jarvis et al., 1994). Simulations of pesticide concentrations between events are less accurate (Renaud and Brown, submitted). Several improvements are currently being considered including: (a) the inclusion of a groundwater store that would interact with streams; (b) a more refined description of fate of pesticides in ditches (particularly diffusion into sediment and sorption to macrophytes); and (c) a full graphical user interface. 


\section{References}

Allen, R.G., Pereira, L.S. , Raes, D., Smith, M., 1998. Crop evapotranspiration: Guidelines for computing crop water requirements. Food and Agriculture Organization (FAO) Irrigation and Drainage Paper 56, FAO, Rome.

Arnold, J.G., Srinivasan, R., Muttiah, R.S., Williams, J.R., 1998. Large area hydrologic modeling and assessment. Part I: Model development. Journal of the American Water Resources Association $34: 73-89$.

Borg, H., Grimes, D.W., 1986. Depth development of roots with time: An empirical description. Transactions of the American Society of Agricultural Engineers 29:194-197.

Brown, C.D., Bellamy, P.H. \& Dubus, I.D., 2002. Prediction of pesticide concentrations found in rivers in the UK. Pest Management Science 58:363-373.

Carsel, R.F., Imhoff, J.C., Hummel, P.R., Cheplick, J.M., Donigian, A.S., 2000. PRZM-3, A model for predicting pesticide and nitrogen fate in the crop root and unsaturated soil zones: Users manual for release 3.0. National Exposure research Laboratory, US EPA, Athens GA.

Chapra, S.C. 1997. Surface water-quality modelling. WCB/McGraw-Hill, Boston, MA.

Dickinson, R.E. 1984. Modeling evapotranspiration for three-dimensional global climate models. In: Climate processes and climate sensitivity (J.E. Hansen and T. Takahashi, eds). AGU Geophysical Monograph 29, pp58-72.

Environment Agency, 2003. Pesticide detection results for 2003. Available on www.environmentagency.gov.uk.

Evans, S.P., T.R. Mayr, J.M. Hollis and C.D. Brown. 1999. SWBCM: A soil water balance capacity model for environmental applications in the UK. Ecological Modelling 121:17-49.

Flury, M., 1996. Experimental evidence of transport of pesticides through field soils - a review. Journal of Environmental Quality 25:25-45. 
Fread, D.L. 1993. Flow routing. In: Handbook of hydrology (D.R. Maidment, ed.). McGraw-Hill, New York, pp. 10.1-10.36.

FOCUS, 2002. FOCUS Surface Water Scenarios in the EU Evaluation Process under 91/414/EEC. Report of the FOCUS Working Group on Surface Water Scenarios, EC Document Reference SANCO/4802/2001-rev.2, European Commission, Brussels, Belgium.

Hand, L.H., Kuet, S.F., Lane, M.C.G., Maund, S.J., Warinton, J.S., Hill, I.R. 2001. Influences of aquatic plants on the fate of the pyrethroid insecticide lambda-cyhalothrin in aquatic environments. Environmental Toxicology and Chemistry 20:1740-1745.

Hillel, D. 1998. Environmental soil physics. Academic Press, San Diego, CA.

Hutson, J.L., Wagenet, R.J., 1992. LEACHM. A process-based model of water and solute movement, transformations, plant uptake and chemical reactions in the unsaturated zone. Cornell University, Ithaca, NY.

IFEN (2002). Pesticides in water No. 42. Sixth annual report. IFEN, Orléans, France.

Jarvis, N.J., 1994. The MACRO model (Version 3.1). Technical description and sample simulations. Reports and dissertations 19, Department of Soil Sciences, Swedish University of Agricultural Sciences, $51 \mathrm{pp}$.

Larsbo, M., Jarvis, N., 2003. MACRO 5.0. A model of water flow and solute transport in macroporous soils. Technical description. Swedish University of Agricultural Sciences, Uppsala, Sweden.

Moore, M.T., Bennett, E.R., Cooper, C.M., Smith, S., Shields, F.D., Milam, C.D., Farris, J.L. 2001. Transport and fate of atrazine and lambda-cyhalothrin in an agricultural drainage ditch in the Mississippi Delta, USA. Agriculture Ecosystems and Environment 87:309-314.

Müller, C. 2000. Modelling soil-biosphere interactions. CABI Publishing, Wallingford, UK.

Neitsch, S.L., Arnold, J.G., Kiniry, J.R., Williams, J.R., King, K.W. 2002. Soil and Water Assessment Tool theoretical documentation. Version 2000. Agricultural Research Service, Temple TX.

Refsgaard, J.C. and B. Storm. 1995. MIKE SHE. In: Computer models of watershed hydrology (V.P. Singh, ed.). Water Resources Publications, Highland Ranch, CO, pp. 809-846. 
Renaud, F.G., Brown, C.D., submitted. Simulating pesticides in ditches to assess ecological risk (SPIDER): II. Comparison of two field transport models. Science of the Total Environment.

Sloan, P.G., Moore, I.D., 1984. Modeling subsurface stormflow on steeply sloping forested watersheds. Water Resources Research 20:1815-1822.

Styczen, M., Petersen, S., Olsen, N.K. and Andersen, M.B. 2004. Technical documentation of PestSurf, a model describing fate and transport of pesticides in surface water for Danish Conditions. - Ministry of Environment, Danish Environmental Protection Agency, Pesticides Research No. 64.

Viessman Jr, W. and G.L. Lewis. 1996. Introduction to hydrology. 4th Edition, Harper Collins College Publishers, NY, $760 \mathrm{p}$.

Wauchope R.D., 1996. Pesticides in runoff: measurement, modelling and mitigation. Journal Environment Science Health B 31:337-344.

Walker, A., 1973. Use of a simulation model to predict herbicide persistence in the field. In: Proceedings of the European Weed Research Council Symposium Herbicides - Soil, pp.240-250.

Williams, J.R. 1995. Chapter 25: The EPIC model. p. 909-1000. In V.P. Singh (ed.). Computer models of watershed hydrology. Water Resources Publications.

Williams, W.M., C.E. Zdinak, A.M. Ritter, J.M. Cheplick, and P. Singh, 1999. RIVWQ: Chemical Transport Model for Riverine Environments. Users Manual and Program Documentation, Version 2.00, Waterborne Environmental, Inc., Leesburg, Virginia, USA.

Wu, J. and D.L. Nofziger. 1999. Incorporating temperature effects on pesticide degradation into a management model. Journal of Environmental Quality 28:92-100. 
1 Table 1. Classification of pesticide fate models that might be considered for use in simulating small agricultural catchments (adapted from FOCUS, 2006).

\begin{tabular}{|c|c|c|}
\hline Type of model & Examples & Potential for use at the catchment scale \\
\hline $\begin{array}{l}\text { One-dimensional ("unit area") } \\
\text { soil column leaching and/or } \\
\text { surface runoff models }\end{array}$ & $\begin{array}{c}\text { CHAIN_2D, LEACHM, } \\
\text { MACRO, PEARL, } \\
\text { PELMO, PRZM, TETrans }\end{array}$ & $\begin{array}{l}\text { Models lack the capability of simulating } \\
\text { surface processes and/or are restricted in } \\
\text { scale by the unit area approach }\end{array}$ \\
\hline $\begin{array}{l}\text { Field-scale models of } \\
\text { hydrological flow, and nutrient } \\
\text { and/or pesticide fate }\end{array}$ & $\begin{array}{c}\text { EPIC, GLEAMS, Opus, } \\
\text { RZWQM }\end{array}$ & $\begin{array}{l}\text { Models are limited to field-scale simulations } \\
\text { and do not provide representation of flow } \\
\text { routing to low order streams and ditches. In } \\
\text { addition, they do not provide adequate } \\
\text { representation of spatial variability typically } \\
\text { present in catchments. }\end{array}$ \\
\hline $\begin{array}{l}\text { Catchment-scale models of } \\
\text { hydrological flow and nutrient } \\
\text { and/or pesticide fate. }\end{array}$ & $\begin{array}{l}\text { AGNPS, ANSWERS- } \\
\text { 2000, CATFLOW, HSPF, } \\
\text { MIKE-SHE, SWAT, } \\
\text { SWATCATCH }\end{array}$ & $\begin{array}{l}\text { All models include capability of flow routing } \\
\text { and spatial heterogeneity. }\end{array}$ \\
\hline
\end{tabular}




(

$3 A_{r}$

4 Amp

$5 a$

6

7

8

9

10

FC

$f$

$f_{m a}$

\section{Appendix 1: Nomenclature}

\begin{tabular}{|c|c|c|}
\hline$A$ & $\mathrm{~m}^{2}$ & Cross sectional area of flow \\
\hline$A_{r}$ & $\mathrm{~kg} \mathrm{ha}^{-1}$ & Pesticide application rate \\
\hline$A m p$ & ${ }^{\circ} \mathrm{C}$ & Temperature amplitude at the soil surface \\
\hline$a$ & - & $y$-intercept of the basic spray drift equation $(=3.7676)$ \\
\hline$B$ & - & Moisture exponent (set at 0.7 ) \\
\hline$B F$ & $\mathrm{~m}^{3}$ & Baseflow \\
\hline$b$ & - & Exponent of the basic spray drift equation above $(=-09786)$ \\
\hline$C$ & $\mathrm{~J} \mathrm{~m}^{-3} \mathrm{~K}^{-1}$ & Specific heat of soil constituents \\
\hline$C A$ & - & Angle correction factor \\
\hline$c$ & $\mathrm{~m} \mathrm{~s}^{-1}$ & Kinematic wave velocity \\
\hline$D$ & $\mathrm{~mm}$ & Drainage depth \\
\hline$D_{f}$ & $\%$ & Final percent drift entering the water body \\
\hline$D_{0}$ & $\%$ & Basic integrated spray drift \\
\hline$D_{r}$ & $\mathrm{~mm}$ & Root zone depletion \\
\hline Deg & $\mathrm{mg}$ & $\begin{array}{l}\text { Amount of pesticide lost on the crop canopy via degradation and other } \\
\text { loss mechanisms }\end{array}$ \\
\hline Disch & $\mathrm{m}^{2} \mathrm{~h}^{-1}$ & Discharge \\
\hline$D L$ & $\mathrm{~m}$ & Ditch length \\
\hline$D P D$ & $\mathrm{mg}$ & Pesticide degradation in ditch \\
\hline$D P I$ & $\mathrm{mg}$ & Pesticide input to the ditch \\
\hline$D P L$ & $\mathrm{mg}$ & Pesticide percolation through ditch sediment \\
\hline$D P O$ & $\mathrm{mg}$ & Pesticide load transmitted to next ditch or reaching catchment outlet \\
\hline$D P T L$ & $\mathrm{mg}$ & Pesticide load in the ditch (pesticide in water and in sediment) \\
\hline$D R$ & $\mathrm{~m}^{3}$ & Volume of rain falling on a ditch \\
\hline DrainabPor & - & Drainable porosity \\
\hline DrainabVol & $\mathrm{m}^{2}$ & Drainable volume of water stored in the saturated zone per unit width \\
\hline DrL & $\mathrm{mg}$ & Pesticide load in drainage \\
\hline$D S$ & $\mathrm{~mm}$ & Thickness of the saturated layer \\
\hline$D W$ & $\mathrm{~m}$ & Ditch width \\
\hline$d$ & $\mathrm{~m}$ & Flow depth \\
\hline$d_{c}$ & $\mathrm{~m}$ & Depth of ditch \\
\hline$d d$ & $\mathrm{~mm}$ & Damping depth at which the temperature decreases to the fraction $1 / e$ \\
\hline depth & $\mathrm{mm}$ & Depth of the soil layer \\
\hline
\end{tabular}

E $\mathrm{m}^{3}$

$\mathrm{Ea} \quad \mathrm{J} \mathrm{mol}^{-1}$

Ecan $\mathrm{mm}$

$\begin{array}{ll}E T_{a} & \mathrm{~mm} \mathrm{~h}^{-1}\end{array}$

$E T_{r} \quad \mathrm{~mm} \mathrm{~d}^{-1}$

$e_{a} \quad \mathrm{kPa}$

$e_{s} \quad \mathrm{kPa}$

FCC

FieldL

FlowVel

FracRoot

Cross sectional area of flow

Temperature amplitude at the soil surface

$y$-intercept of the basic spray drift equation $(=3.7676)$

Moisture exponent (set at 0.7 )

Baseflow

Specific heat of soil constituents

Angle correction factor

Drainage depth

Amount of pesticide lost on the crop canopy via degradation and other loss mechanisms

Discharge

Ditch length

Pesticide percolation through ditch sediment

Pesticide load transmitted to next ditch or reaching catchment outlet

Pesticide load in the ditch (pesticide in water and in sediment)

Drainable volume of water stored in the saturated zone per unit width

Pesticide load in drainage

Thickness of the saturated layer

Flow depth

Depth of the soil layer

Volume of evaporation from a ditch

Activation energy (set at $54000 \mathrm{~J} \mathrm{~mol}^{-1}$ )

Depth of water lost from the canopy by evaporation

Actual evapotranspiration

Daily reference evapotranspiration

Actual vapour pressure

Saturation vapour pressure

Foliar extraction coefficient

Fraction of crop cover

Field length

Flow velocity

Fraction of the soil layer occupied by crop roots

Fraction of soil constituents

Fraction of the total sorption capacity of the soil that is associated with macropores 


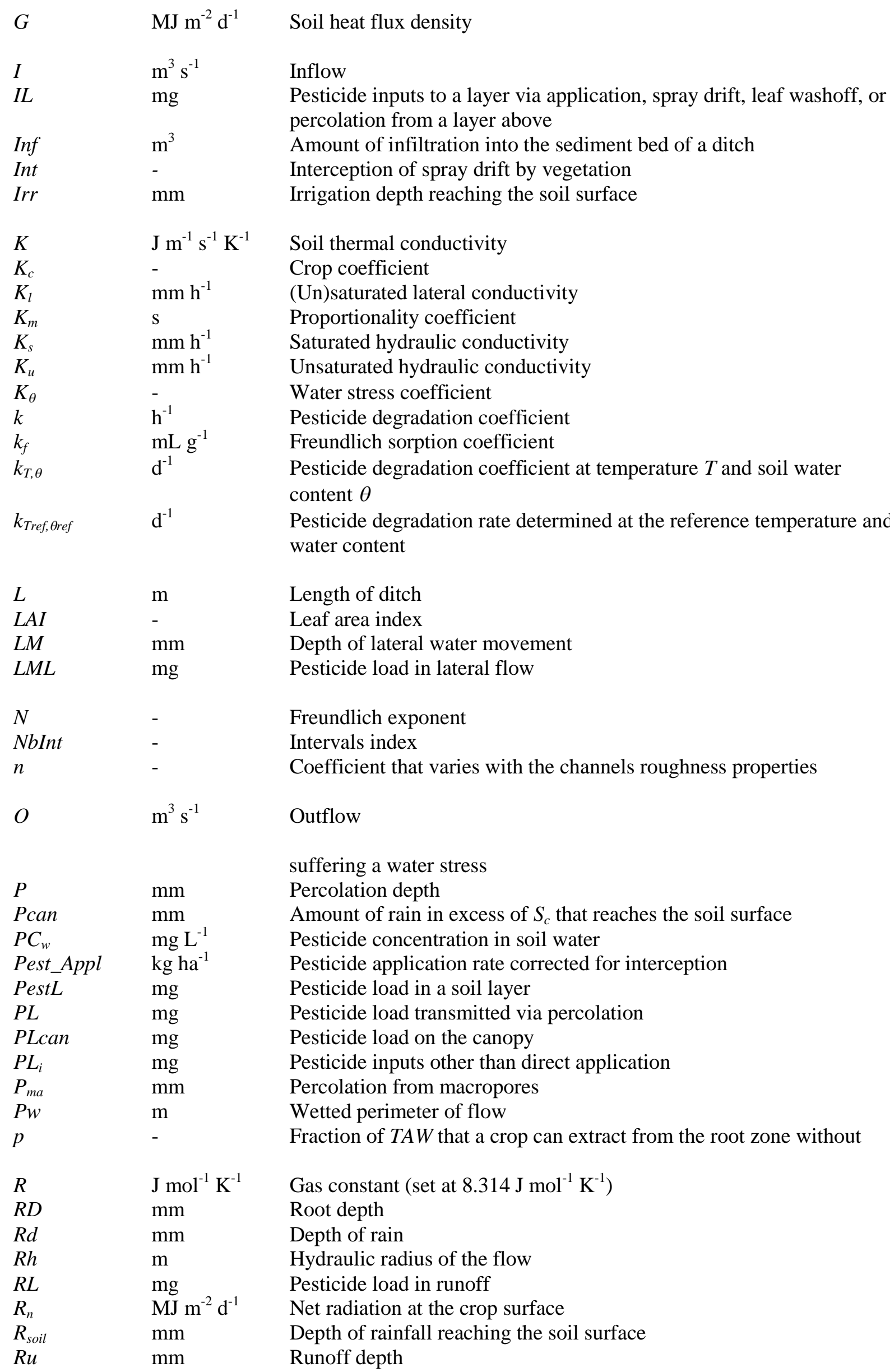




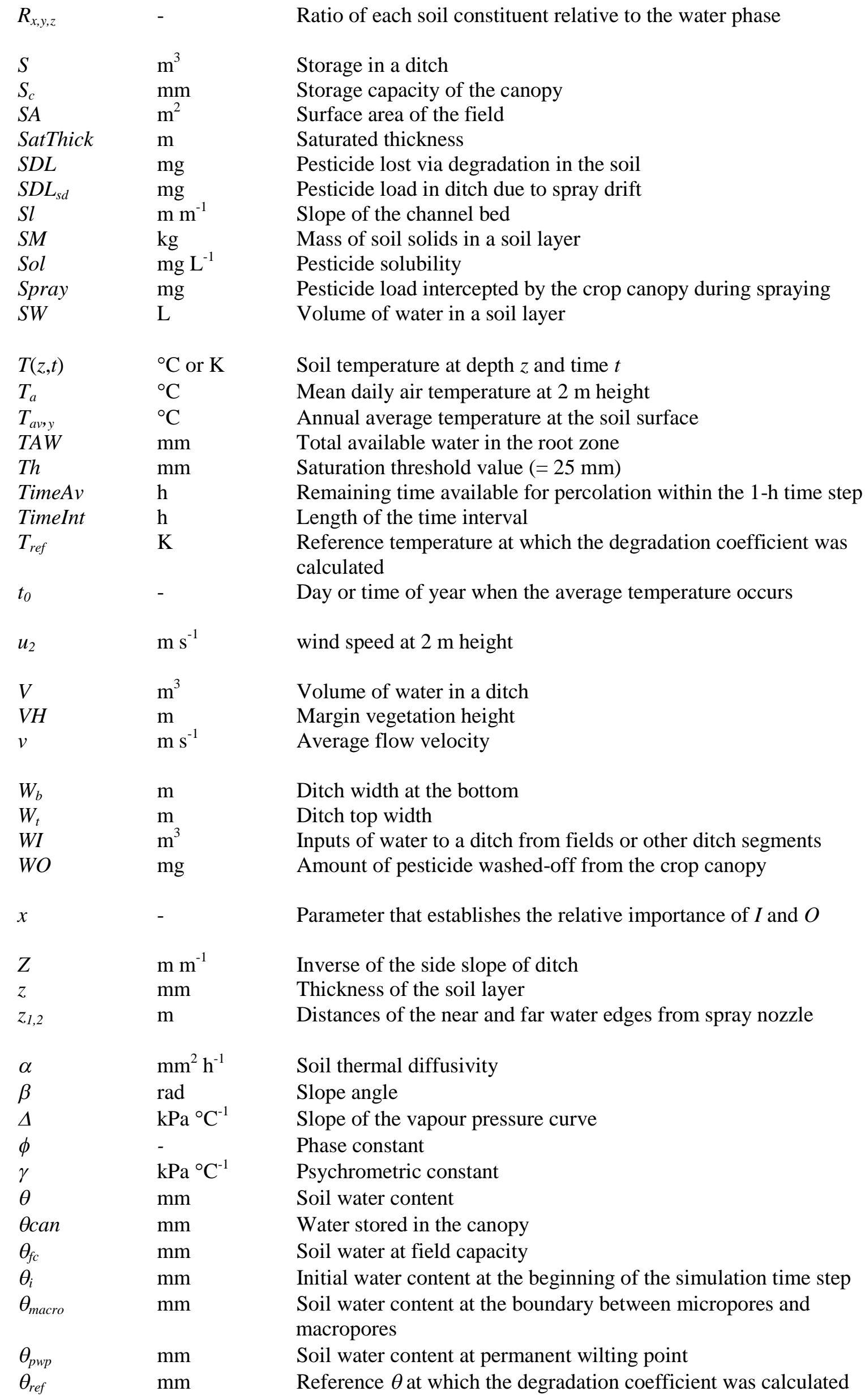$$
R_{x, y, z}
$$$$
S \quad \mathrm{~m}^{3}
$$$$
\begin{array}{ll}
S_{c} & \mathrm{~mm}
\end{array}
$$$$
\text { SA } \mathrm{m}^{2}
$$$$
\text { SatThick m }
$$$$
S D L \quad \mathrm{mg}
$$$$
S D L_{s d} \quad \mathrm{mg}
$$$$
S l
$$$$
\text { SM }
$$$$
\text { Sol }
$$$$
\text { Spray }
$$$$
\text { SW }
$$$$
T(z, t)
$$$$
T_{a}
$$$$
T_{a v, y}
$$$$
\text { TAW }
$$$$
\text { Th }
$$$$
\text { TimeAv }
$$$$
\text { TimeInt }
$$$$
T_{r e f}
$$$$
t_{0}
$$$$
u_{2}
$$$$
\text { V }
$$$$
\text { VH }
$$$$
\text { v }
$$$$
W_{b}
$$$$
W_{t}
$$$$
\text { WI }
$$$$
\text { WO }
$$$$
x
$$$$
\text { Z }
$$$$
z
$$$$
z_{1,2}
$$$$
\alpha
$$$$
\beta
$$$$
\Delta
$$$$
\phi
$$$$
\gamma
$$$$
\theta
$$

$\theta$ can

$\theta_{f c}$

$\theta_{i}$

$\theta_{\text {macro }}$

$\theta_{p w p}$

$\theta_{\text {ref }}$

$\mathrm{m}^{3}$

$\mathrm{m}^{2}$

$\mathrm{mg}$

$\mathrm{m} \mathrm{m}^{-1}$

$\mathrm{kg}$

$\mathrm{mg} \mathrm{L}^{-1}$

$\mathrm{mg}$

L

${ }^{\circ} \mathrm{C}$ or K

${ }^{\circ} \mathrm{C}$

${ }^{\circ} \mathrm{C}$

$\mathrm{mm}$

$\mathrm{mm}$

$\mathrm{h}$

$\mathrm{h}$

K

$\mathrm{m} \mathrm{s}^{-1}$

$\mathrm{m}^{3}$

$\mathrm{m}$

$\mathrm{m} \mathrm{s}^{-1}$

$\mathrm{m}$

$\mathrm{m}$

$\mathrm{m}^{3}$

$\mathrm{mg}$

$\mathrm{m} \mathrm{m}^{-1}$

$\mathrm{mm}$

$\mathrm{m}$

$\mathrm{mm}^{2} \mathrm{~h}^{-1}$

$\mathrm{rad}$

$\mathrm{kPa}{ }^{\circ} \mathrm{C}^{-1}$

-

$\mathrm{kPa}{ }^{\circ} \mathrm{C}^{-1}$

$\mathrm{mm}$

$\mathrm{mm}$

$\mathrm{mm}$

$\mathrm{mm}$

$\mathrm{mm}$

$\mathrm{mm}$

$\mathrm{mm}$

Ratio of each soil constituent relative to the water phase

Storage in a ditch

Storage capacity of the canopy

Surface area of the field

Saturated thickness

Pesticide lost via degradation in the soil

Pesticide load in ditch due to spray drift

Slope of the channel bed

Mass of soil solids in a soil layer

Pesticide solubility

Pesticide load intercepted by the crop canopy during spraying

Volume of water in a soil layer

Soil temperature at depth $z$ and time $t$

Mean daily air temperature at $2 \mathrm{~m}$ height

Annual average temperature at the soil surface

Total available water in the root zone

Saturation threshold value $(=25 \mathrm{~mm})$

Remaining time available for percolation within the 1-h time step

Length of the time interval

Reference temperature at which the degradation coefficient was calculated

Day or time of year when the average temperature occurs

wind speed at $2 \mathrm{~m}$ height

Volume of water in a ditch

Margin vegetation height

Average flow velocity

Ditch width at the bottom

Ditch top width

Inputs of water to a ditch from fields or other ditch segments

Amount of pesticide washed-off from the crop canopy

Parameter that establishes the relative importance of $I$ and $O$

Inverse of the side slope of ditch

Thickness of the soil layer

Distances of the near and far water edges from spray nozzle

Soil thermal diffusivity

Slope angle

Slope of the vapour pressure curve

Phase constant

Psychrometric constant

Soil water content

Water stored in the canopy

Soil water at field capacity

Initial water content at the beginning of the simulation time step

Soil water content at the boundary between micropores and

macropores

Soil water content at permanent wilting point

Reference $\theta$ at which the degradation coefficient was calculated 


$\begin{array}{llll}1 & \theta_{\text {sat }} & \mathrm{mm} & \text { Soil water content at saturation } \\ 2 & \theta_{v} & \mathrm{~mm}^{3} \mathrm{~mm}^{-3} & \text { Soil volumetric water content } \\ 3 & \omega & \mathrm{h}^{-1} \text { or d}^{-1} & \text { Radial frequency }\end{array}$

4

5

6

7 